\title{
GIS-Based Analysis on Transportation Network Features of Garden City Model
}

\author{
Zhiyuan Yuan, XinqiZheng*, Jikang Zhang \\ Department of Land Science \& Technology, \\ China University of Geoscience \\ Beijing,China \\ fightziyuan@163.com \\ *corresponding author, zxqsd@126.com
}

\begin{abstract}
Network structure is generally used to represent and study urban transportation system. This research works on the digital model of classical planning theory Garden City, and calculates the network macroscopic topological properties of radial and ringy crossing urban transportation system. The extraction of topology structure of the digital Garden City and the calculation and analysis of topology parameters of the transportation system including degree, clustering coefficients and $\mathrm{K}$-Core are the main two parts of the research. Conclusions can be drawn that highervalued nodes for the three parameters are basically coincident, which mainly are the crossings of the first, second and third avenues and boulevards and streets.Further research on digital Garden City's transportation system would be meaningful.
\end{abstract}

Key words-Transportation system, complex network, Topological parameters, Garden City.

\section{INTRODUCTION}

Urban form is significant in researches on urban planning and urban geography. As the framework of urban structure, transportation network comes to be an important part of urban space[1]. Quantitative estimation on transportation network is critical for the controllable parameter study of urban space form[2]. As the development of complex network and graph theory, GIS topology and complex network model have been widely used in researches on urban transportation network, objects mainly included single means of transportation such as railway and shipping[3,4], urban public transportation system[5], transportation network of urban agglomeration[6], and so on. All of which offer foundations for excavating evolution mechanism of urban transportation network and improving and optimizing network design.

Garden City, brought by E.Howard in the end of 18th century, is recognized worldly as a classical typical planning theory, which is significant in studies on evolution of urban agglomeration, relations between urbanization and ecology and urban planning[7,8]. The transportation system of Garden City is the theory classic of the intersect layout of radial pattern and rings, which have been widely used in the world. However, restricted by the topography and the city's history, the intersect network existed are all transformative and lack of representation. Based on GIS topology and complex network parameters, once the calculation and analysis can be organized directly in Garden
City, the results would be ideal and non-intrusive, which can prove further researches on urban transportation system's planning and optimizing.

Based on digital Garden City, which was built in the teams former studies, this research firstly extracts the transportation network's topology structure in GIS; secondly, based on complex network parameters of degree, clustering coefficients and K-Core, the characteristics of the transportation system are calculated in PAJEK software. At last, according to analysis on the results, discussion on the original Garden City's transportation system planning is conducted.

\section{METHOD}

\section{Extraction of Transportation Network Topology Structure}

Extracting the topology structure of the transportation network means to abstract the different traffic classes in Howard's planning into a topological graph. According to the original planning, all roads are two-way, and the assumption is locals' choice of traffic is free in the city, thus the topological graph should be a weighted undirected graph, and the distance between neighboring points is the weight. The extraction of topology structure in this research is based on the model of digital Garden City, which was built in the former research of the team[9]. The model was built based on critical processes of abstraction model objectives, establishment of mathematical basis, data preparation, physical structure design, vectorization and calibration. Points, lines and polygons, which constitute figures in GIS, have topological properties. The method of Space $P$ [10]is used based on the fact of the roads, that is take the crossings and start points (connecting with other layouts but roads) as nodes, and the arcs is created while it's linked directly between two nodes. The arcs follow center lines of the roads. Though processes of clip or extend lines and topology examine, the topology structure was exacted. Besides, with the geometry statistical function of ArcGIS software, the network description matrix can be obtained following the route of the starting node and ending ones of arcs. Moreover, for the patterns of the roads are rings, the cow distance was used here instead of crow distance[11]. 
FORMULA AND EXPLANATIONS OF FEATURE PARAMETERS USED

\begin{tabular}{|c|c|c|c|c|c|}
\hline \multicolumn{2}{|c|}{ Feature parameters } & Signal & Formula & Definition & Meaning \\
\hline Degree & Degree & $\mathrm{k}_{\mathrm{i}}$ & $k_{i}=\sum \delta_{i j}$ & Number of nodes that linked with node i & Judging on the importance of the nodes \\
\hline \multirow{2}{*}{$\begin{array}{l}\text { Clustering } \\
\text { coefficient }\end{array}$} & $\begin{array}{l}\text { Clustering } \\
\text { coefficient }\end{array}$ & $c_{i}$ & $C_{i}=\frac{2 E_{i}}{k_{i}\left(k_{i}-1\right)}$ & $\begin{array}{l}\text { If there the number of nodes directly linked } \\
\text { with node } i \text { isk } k_{\mathrm{i}} \text {, then the } \mathrm{c}_{\mathrm{i}} \text { is the ratio of existed } \\
\text { edges } \mathrm{E}_{\mathrm{i}} \text { and possible edges } \mathrm{k}_{\mathrm{i}}\left(\mathrm{k}_{\mathrm{i}}-1\right) / 2\end{array}$ & $\begin{array}{l}\text { Its distribution reflects the intensive } \\
\text { situation of each crossing }\end{array}$ \\
\hline & $\begin{array}{l}\text { Average of } \\
\text { clustering } \\
\text { coefficient }\end{array}$ & CC & $\mathrm{CC}=\frac{\sum_{i=1}^{N} C_{i}}{N}$ & $\begin{array}{l}\text { Average of clustering coefficients of all nodes } \\
\text { in the network }\end{array}$ & $\begin{array}{l}\text { Reflecting the intensive degree of the } \\
\text { whole network }\end{array}$ \\
\hline K-Core & K-Core & - &  & $\begin{array}{l}\text { For a network, if any node has no less than } \mathrm{k} \\
\text { neighboring nodes, then the network can be } \\
\text { named as K-Core network. }\end{array}$ & $\begin{array}{l}\text { Core nodes are closely linked, while others } \\
\text { linked with them just via few edges. } \\
\text { Extraction of all the K-Core network can } \\
\text { point out all the important nodes of the } \\
\text { network for more attention. }\end{array}$ \\
\hline
\end{tabular}

\section{Calculation on characteristics of transportation complex network}

So many statistical parameters can be used to describe the structure properties of complex network, such as degree, average path length, network density, clustering coefficients, global efficiency, and so on ${ }^{[7]}$. Limited by the space, three basic but important parameters are calculated here on transportation system of Garden City, that is degree, clustering coefficient and $\mathrm{K}$-core (Table I ). The calculation is organized by PAJEK software with a preparation of topology structure files.

\section{RESULTS}

\section{Transportation Network Topology of Garden City}

After extraction and processing of .shp files relating to transportation system, the transportation network of Garden City was obtained (Fig.1). The topology mainly consists of 5different traffic structure: 6 boulevards, 12 streets and 18 roads which are of radial pattern, and 5avenues and 1railway around the city which are rings. There are 186 nodes in the topology in total. And the structure is significantly central symmetry.

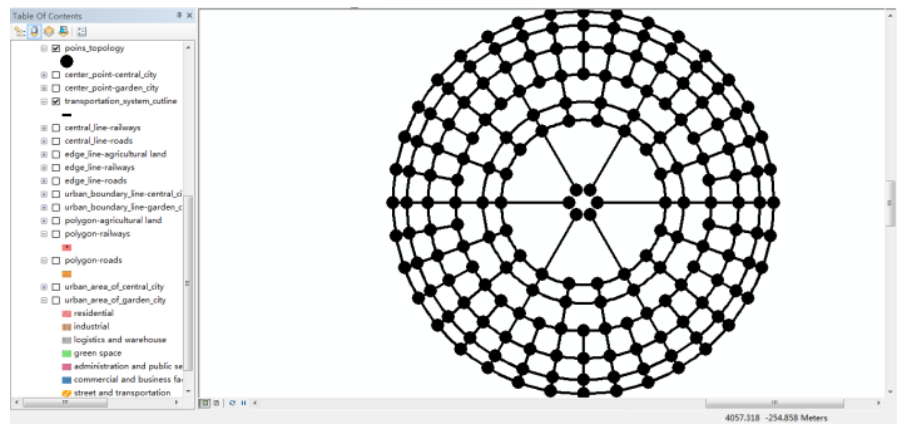

Fig. 1. Topology structure of Garden City's transportation system

Based on the topology structure and geometry properties, formed the topology matrix of cow distance. The original drawing network of the matrix is as follow (Fig .2)



Fig. 2. Network drawn in PAJEK based on topology files

\section{Characteristics of transportation network}

DEGREE:According to the results of the calculation, the degree values of the nodes range from 12 to 83 . By join the values with the digital model, the statistical and spatial distribution is clear (Fig.3 andTable II). Conclusions could be drawn that distance to city centre and the class of the radial pattern roads are the main two factors on spatial distribution of nodes, and the relations are both positive correlation. Nodes with maximal degree values are the crossings of boulevards and the first, second and third avenue, representing that the corresponding road junctions in the city are the most impotrant ones for the transportation network.

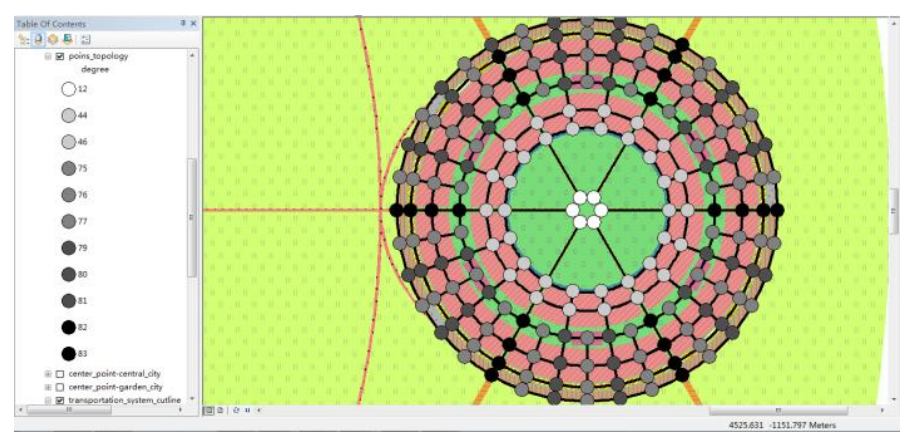

Fig. 3. Spatial distribution of nodes' degree 
THE COUNT AND SPATIAL DISTRIBUTION OF DEGREE

\begin{tabular}{|c|c|c|}
\hline degree & count & locations \\
\hline 12 & 6 & Start nodes of boulevards \\
\hline 44 & 24 & Crossings of streets and 4th and 5th avenues \\
\hline 46 & 12 & Crossings of boulevards and 4th and 5th avenues \\
\hline 75 & 18 & Crossings of roads and the railway \\
\hline 76 & 36 & Crossings of roads and 2nd and 3rd avenues \\
\hline 77 & 18 & Crossings of roads and 1st avenue \\
\hline 79 & 12 & Crossings of streets and the railway \\
\hline 80 & 24 & $\begin{array}{c}\text { Crossings of streets and 2nd and 3rd avenues } \\
\text { Crossings of streets and 1st avenue } \\
\text { The crossing of boulevard(just 1/6)and railway }\end{array}$ \\
\hline 81 & 13 & $\begin{array}{c}\text { Crossings of boulevards and 1st,2nd and 3rd avenues } \\
\text { and the railway(except the one in above blank and the } \\
\text { one in below blank) }\end{array}$ \\
\hline 83 & 1 & \begin{tabular}{c} 
The crossing of boulevard(just 1/6) and 1st avenue \\
\hline
\end{tabular}
\end{tabular}

CLUSTERING COEFFICIENT:It can be seen that the clustering coefficients of nodes are ranges from $0.4-1$, and 0.75 0.85 are the most intensive interval. Connecting with their spatial situations, the distribution of the clustering features is random, while the class of the radial pattern roads is still impactive to some extent. The nodes with relatively high values of clustering features mainly are crossings of boulevards and streets with the first,second and third avenue, which is in accordance with the higher nodes in degree distribution.Additionally, the average of the network's clustering coefficients is 0.77 , which means the transportation system is relatively crowding in terms of overall.

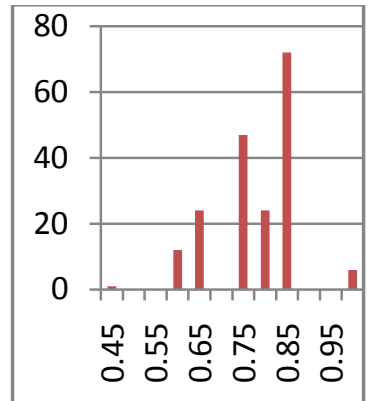

Fig. 4. Statistics of clustering coefficients of all notes

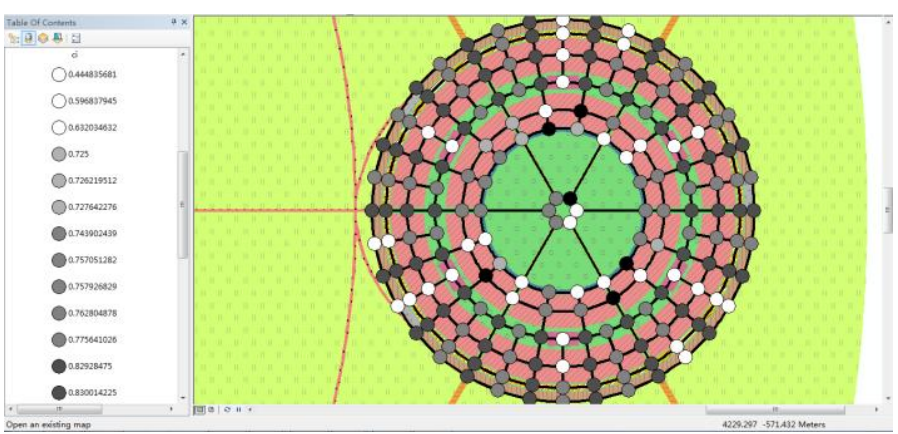

Fig. 5. Spatial distribution of nodes'clustering coefficients

$K \_C O R E$ :Accoding to the results, there are only $3 \mathrm{~K}$-Core values, that is 12,44 and 75 . The value is significantly affected by which rings the crossings are located.The K-Cores of boulevards' starting nodes are 12, crossings on the forth and fifth avenue is 44 , while nodes on the first, second and third avenue and the railway is 75 . Thus, nodes on these four outer rings are the core ones of the transportation network, which is in accordance with the calculation results of degree and clustering coefficients.

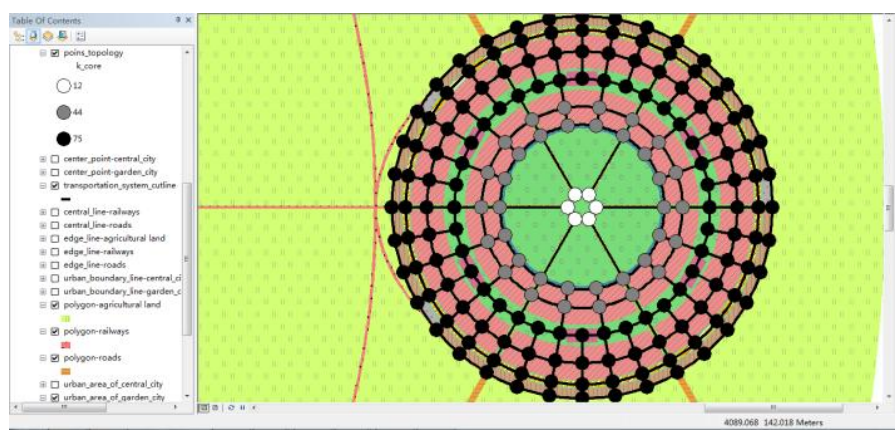

Fig. 6. Spatial distribution of nodes’ K-Cores

\section{CONCLUSION AND DISCUSSION}

Transportation system of Garden City is a classical and typical model for the crossing structure of radial roads andringy ones. Through the extraction of topology structure and the calculation on several parameters of complex network, the research measured and analyzed the network features and spatial distribution of ideal crossing transportation system of radial and ringy roads. Conclusions can be drawn that the higher-valued nodes for degree, clustering coefficient and K-Core are basically coincident, which mainly are the crossings of the first, second and third avenues and boulevards and streets. Instead of located in areas such as the commercial center-the Crystal Palace, or the logistic areas-the railway and industrial ring, the most important nodes in the transportation network are surrounding the outer two residential rings, and inner adjoining the industrial rings.

Limited by the space, the research just organized preliminary estimation on Garden City's transportation system network. 
Further study can be conducted from different perspectives including:

- With theories of fractal features or hierarchical topology, digging deeper into the network features of Garden City's transportation system.

- $\quad$ Simulating and evolutingthe traffic system while taking the population distribution and traffic flow into account.

\section{REFERENCES}

[1] Huang Pei-bei and Liu Miao-long, “GIS-based study on fractal features of urban traffic network in Shanghai," Journal of Tongji University (Natural Science), vol. 11, pp. 1370-1374, 2002.

[2] LI Jiang and GUO Qin-sheng, “Quantitative representing complexity of urban traffic network base on GIS" , Journal of Huazhong Normal University (Natural Sciences), vol. 04, pp. 534-537,2002.

[3] Fernando González Laxe, Maria Jesus FreireSeoane and Carlos Pais Montes, "Maritime degree, centrality and vulnerability: port hierarchies and emerging areas in containerized transport (20082010)", Journal of Transport Geography, Vol 24, pp. 33-44, September, 2012.

[4] Antonio Doménech, "A topological phase transition between small-worlds and fractal scaling in urban railway transportation networks?",Physica A: Statistical Mechanics and its Applications, Vol 388, pp. 4658-4668, November, 2009.

[5] Alejandro Tirachini, David A. Hensher and Sergio R. Jara-Díaz, "Comparing operator and users costs of light rail, heavy rail and bus rapid transit over a radial public transport network", Research in Transportation Economics, Vol.29, pp. 231-242, 2010.

[6] Xinsheng SONG, Xiaoxiao WANG, aizeng LI and Lei ZHANG, "Node importance evaluation method for highway network of
- Extracting the topology structure of the whole Society City to organize calculation and analysis on city agglomeration's transportation system network.

\section{ACKNOWLEDGMENT}

This research was supported by the National Public Benefit (Land) Research Foundation of China (No. 201111014). urban agglomeration", Journal of Transportation Systems Engineering and Information Technology, Vol.11, pp. 84-90, April 2011.

[7] FANG Chuanglin, SONG Jitao, ZHANG Qiang and LI Ming, "The formation, development and spatial heterogeneity patterns for the structures system of urban agglomerations in China" , ActaGeographicaSinica, Vol.05, pp. 827-840, 2005.

[8] LIU Yao-bin, LI Ren-dong and SONG Xue-feng, “Summarary and comment of the correlation study of urbanization and urban eco-environment " , China Population Resources and Environment, Vol.03, pp. 55-60, 2005.

[9] Zhiyuan Yuan, XinqiZheng and ChunluXue, "Modeling and application of digital Garden City based on GIS", unpublished.

[10] LIU Rui, YAN Bao-jie and HUANG Zhi-peng, “Complexity analysis of urban public transit network" , Journal of Transportation Systems Engineering and Information Technology, Vol.09, pp. 17-22, 2009.

[11] Kaye BH, "A random walk through fractal dimensions", VCH Verlagsgesell Shaft, Germany, 1989.

[12] WANG Guo-ming, LI Xia-miao, YANG Bo and HU Zhengdong, "The properties of traffic networks in urban agglomeration", Computer Engineering \& Science, Vol.34, pp. 174-182, 2012 